University of Nebraska - Lincoln

DigitalCommons@University of Nebraska - Lincoln

Sociology Department, Faculty Publications

Sociology, Department of

2011

\title{
Are we keeping the people who used to stay? Changes in correlates of panel survey attrition over time
}

\author{
Kristen Olson \\ University of Nebraska-Lincoln, kolson5@unl.edu \\ Lindsey Witt \\ University of Nebraska-Lincoln, witt_lindsey@yahoo.com
}

Follow this and additional works at: https://digitalcommons.unl.edu/sociologyfacpub

Part of the Sociology Commons

Olson, Kristen and Witt, Lindsey, "Are we keeping the people who used to stay? Changes in correlates of panel survey attrition over time" (2011). Sociology Department, Faculty Publications. 143.

https://digitalcommons.unl.edu/sociologyfacpub/143

This Article is brought to you for free and open access by the Sociology, Department of at DigitalCommons@University of Nebraska - Lincoln. It has been accepted for inclusion in Sociology Department, Faculty Publications by an authorized administrator of DigitalCommons@University of Nebraska - Lincoln. 
Published in Social Science Research 40:4 (July 2011), pp. 1037-1050; doi: 10.1016/j.ssresearch.2011.03.001

Copyright (C) 2011 Elsevier Inc. http://www.elsevier.com/locate/ssresearch Used by permission.

\title{
Are we keeping the people who used to stay? Changes in correlates of panel survey attrition over time
}

\author{
Kristen Olson \\ Survey Research and Methodology Program, Department of Sociology, \\ University of Nebraska-Lincoln, 703 Oldfather Hall, Lincoln, NE 68588-0324 \\ Corresponding author - fax 402 472-7764, email kolson5@unl.edu \\ Lindsey Witt \\ Survey Research and Methodology Program, University of Nebraska-Lincoln, \\ 201 N. 13th St., Lincoln, NE 68588-0241; email witt lindsey@yahoo.com
}

\begin{abstract}
As survey response rates decline, correlates of survey participation may also be changing. Panel studies provide an opportunity to study a rich set of correlates of panel attrition over time. We look at changes in attrition rates in the American National Election Studies from 1964 to 2004, a repeated panel survey with a two-wave pre-post election design implemented over multiple decades. We examine changes in attrition rates by three groups of variables: sociodemographic and ecological characteristics of the respondent and household, party affiliation and political and social attitudes recorded at the first interview, and paradata about the first wave interview. We find relatively little overall change in the pre-post election panel attrition rates, but important changes in demographic correlates of panel attrition over time. We also examine contact and cooperation rates from 1988 to 2004.
\end{abstract}

Keywords: survey nonresponse, panel attrition, nonresponse bias

\section{Introduction}

A panel study timed around a political election is one common method of conducting an election study. Election studies are conducted to understand who votes and why they vote, and take place in many countries around the world, including the United States, Canada, countries throughout the European Union, Australia and Japan (ANES, 2008). A typical election study asks a random sample of voting age adults about their political and social attitudes immediately before an election. Soon after the election, these pre-election survey respondents are once again asked about their political and social attitudes and-importantly-their voting behavior. These surveys are referred to as pre- and post-election surveys.

Inevitably, some people who participated in the pre-election survey do not participate in the post-election survey. Attrition, or nonresponse to wave two or later of a panel survey, reduces sample size for analyses and biases survey estimates when those who participate are systematically different from those who do not (Bethlehem, 2002; Deming, 1953; Groves and Couper, 1998). Demographic characteristics have been shown to be related to panel attrition, with older people, minorities and males generally more likely to attrite (Aneshensel et al., 1989; Burkam and Lee, 1998; Fitzgerald et al., 1998; Gray et al., 1996; Loosveldt et al., 2002; Lynn et al., 2005; MaCurdy et al., 1998; Mirowsky and Reynolds, 2000; Peracchi, 2002; Sharot, 1991; Watson and Wooden, 2009). Persons with more education and higher income are less likely to attrite (Fitzgerald et al., 1998; Gray et al., 1996; Loosveldt et al., 2002; Lynn et al., 2005; MaCurdy et al., 1998; Mirowsky and Reynolds, 2000; Watson and Wooden, 2009), and persons living in urban areas are more likely to attrite (Gray et al., 1996; Lynn et al., 2005; Watson and Wooden, 2009). Attitudinal measures have also 
been examined as predictors of panel attrition, including social (Waterton and Lievesley, 1987) and political attitudes (Lepkowski and Couper, 2002; Loosveldt and Carton, 1997; Loosveldt et al., 2002). Nonrespondents in election studies tend to be those who are less politically interested or involved in politics (Brehm, 1993; Burden, 2000; Voogt and Saris, 2003; Voogt, 2005).

Different from cross-sectional surveys, sample units to later waves of panel surveys already have experienced at least one interview. As such, characteristics of the previous survey interview also predict panel attrition. Item nonresponse to questions in a previous wave of the study (Burkam and Lee, 1998; Lepkowski and Couper, 2002; Loosveldt and Carton, 1997; Loosveldt et al., 2002; Watson and Wooden, 2009) is associated with higher attrition rates, while the longer interviews in prior waves are associated with higher retention rates (Bogen, 1996).

Although declines in response rates for cross-sectional household surveys over the last four decades are well documented (Curtin et al., 2005; de Leeuw and de Heer, 2002; Steeh, 1981), changes in panel survey attrition rates over these years have been less frequently examined, with limited evidence for declining trends (Agency for Healthcare Research, 2008; Atrostic et al., 2001; Westat, 1998). More importantly, unknown is whether the kinds of people who participate in surveys are changing. To our knowledge, no research has been conducted on whether these factors consistently predict attrition from year to year, holding the wave constant, that is, from wave 1 to wave 2 . In other words, are the types of nonrespondents now different from those from a few decades ago?

Among those social changes with the potential to affect who participates in surveys, women's labor force participation in the US increased substantially with more women working outside the home (Blau, 1998; Dye, 2005; US Census Bureau, 2008). There has been a general aging of the US population (Hobbs and Stoops, 2002), accompanied by an increase in education levels (Stoops, 2004). The racial/ethnic composition of the US also became increasingly nonwhite (Hobbs and Stoops, 2002). Where people live also changed, with a shift back to urban centers, especially in the 1990s and early 2000s (Mackun, 2005). Some of these changes over time can be attributed to historical events spurring social change, others to birth cohort differences, and others to within-individual changes over time (Alwin and McCammon, 2003; Fienberg and Mason, 1979). As the public changes, their views on the value of surveys or time that can be devoted to surveys might change. We hypothesize that these social groups (as defined by sex, race, age, education, and urbanicity) are the most likely to exhibit changes in participation rates over time.

In an election study, participation may be particularly attractive to respondents who are affiliated with certain political parties. We hypothesize that persons whose political party wins a Presidential election will be more likely to cooperate with the post-election survey request. Thus, as political power changes over time, so will cooperation rates. These differences may not be reflected in overall retention rates as we do not expect differences in contact rates over time for different political parties.

This paper examines changes in correlates of post-election survey participation in the American National Election Studies from 1964 to 2004 . We also examine whether there are differences in correlates of making contact with the sampled person and cooperation, conditional on contact, between 1988 and 2004. These analyses permit us to understand whether there is change in characteristics of nonrespondents, and thus the potential for change in nonresponse bias of survey estimates, over these years.

\section{Data and methods}

A repeated panel survey (Kalton and Citro, 1993), in which wave one and wave two of a panel survey are fielded at different points in time, is needed for this study. The American National Election Study (ANES) fits this criterion. The goal of the ANES is to understand voting behavior, political participation and political, social and economic attitudes of American adults.

\subsection{The ANES pre- and post election surveys, 1964-2004}

During presidential election years, the ANES selects a nationally representative sample of voting age adults. These sample units are interviewed in person during the months before the general election, called the "pre-election survey." Respondents to the pre-election survey are reinterviewed during the months following the election, called the "post-election survey."

The ANES pre-post election design has been conducted during presidential election years since 1948. We focus on the 40 years of pre-post election studies from 1964 to 2004 (American National Election Studies, 2004; Burns et al., 2001; Miller et al., 1972, 1993; Miller and American National Election Studies, 1980, 2000a, 2000b; Miller and Miller, 1977; Political Behavior Program, 1968, 1999; Rosenstone et al., 1997); the 2008 ANES was excluded due to a change in the data collection organization. These years were selected to balance longevity of the time series with comparability of the study design over time. We focus only on the fresh cross-section sample for each pre-election survey in each year, excluding the Black oversamples in 1964 and 1968 or panel respondents from previous years. Thus, each year contains an independent sample of the US population during that year, equal probability to the household level. This yields a total number of 16,729 pre-election survey respondents, varying from about 400 to about 2700 respondents in any given year.

Changes in ANES survey procedures and protocol occurred between 1964 and 2004, the most noticeable of which was the decline in the overall pre-election survey response rate (Table 1). Mixed modes of data collection have intermittently been used; computerization was introduced in the 1996 ANES. Finally, across the years, the pre-election sample was released to interviewers all at once, in two random replicates, and in four random replicates. 
Table 1. Selected study characteristics of American National Election Studies, 1964-2004.

\begin{tabular}{|c|c|c|c|c|c|c|c|c|c|}
\hline \multirow[t]{2}{*}{ Year } & \multicolumn{2}{|c|}{ Pre-election } & \multicolumn{3}{|c|}{ Post-election } & \multirow[t]{2}{*}{ Mode } & \multirow[t]{2}{*}{ Computerized } & \multirow{2}{*}{$\begin{array}{l}\text { Other studies or } \\
\text { panels in field at } \\
\text { same time }\end{array}$} & \multirow{2}{*}{$\begin{array}{l}\text { \# Pre- } \\
\text { election } \\
\text { replicates }\end{array}$} \\
\hline & $\begin{array}{l}\text { Response } \\
\text { rate }\end{array}$ & $\begin{array}{l}\text { Sample } \\
\text { size }\end{array}$ & $\begin{array}{l}\text { Retention } \\
\text { rate }\end{array}$ & $\begin{array}{l}\text { Contact } \\
\text { rate }\end{array}$ & $\begin{array}{l}\text { Cooperation } \\
\text { rate }\end{array}$ & & & & \\
\hline 1964 & 80.6 & 1571 & 91.8 & $\mathrm{n} / \mathrm{a}$ & $\mathrm{n} / \mathrm{a}$ & $\begin{array}{l}\text { Face to Face }+ \text { mail } \\
\text { follow-up of NRs in } \\
\text { post-election }\end{array}$ & No & Black supplement & $\mathrm{n} / \mathrm{a}$ \\
\hline 1968 & 77.4 & 1557 & 86.6 & $\mathrm{n} / \mathrm{a}$ & $\mathrm{n} / \mathrm{a}$ & $\begin{array}{l}\text { Face to Face + mail } \\
\text { follow-up of NRs in } \\
\text { post-election }\end{array}$ & No & Black supplement & 2 \\
\hline 1972 & 75.0 & 2705 & 84.5 & $\mathrm{n} / \mathrm{a}$ & $\mathrm{n} / \mathrm{a}$ & Face to face & No & None & 2 \\
\hline 1976 & 70.4 & 1243 & 79.4 & $\mathrm{n} / \mathrm{a}$ & $\mathrm{n} / \mathrm{a}$ & Face to face & No & $\begin{array}{l}1972 \text { and } 1974 \\
\text { respondents }\end{array}$ & $\mathrm{n} / \mathrm{a}$ \\
\hline 1980 & 71.8 & 1614 & 87.2 & $\mathrm{n} / \mathrm{a}$ & $\mathrm{n} / \mathrm{a}$ & Face to face & No & $\begin{array}{l}\text { Many studies, } \\
\text { not panel }\end{array}$ & 4 \\
\hline 1984 & 72.1 & 2257 & 88.1 & $\mathrm{n} / \mathrm{a}$ & $\mathrm{n} / \mathrm{a}$ & $\begin{array}{l}\text { Face to face and } \\
\text { telephone }\end{array}$ & No & $\begin{array}{l}\text { Continuous } \\
\text { monitoring, } \\
\text { not panel }\end{array}$ & 4 \\
\hline 1988 & 70.5 & 2040 & 87.0 & 96.9 & 89.7 & Face to face & No & None & 4 \\
\hline 1992 & 71.4 & 1126 & 89.3 & 96.4 & 92.2 & $\begin{array}{l}\text { Face to face and } \\
\text { telephone }\end{array}$ & No & $\begin{array}{l}1990 \text { and } 1991 \\
\text { respondents }\end{array}$ & 2 \\
\hline 1996 & 60.0 & 398 & 84.7 & 93.0 & 90.8 & $\begin{array}{l}\text { Face to face and } \\
\text { telephone }\end{array}$ & Yes & $\begin{array}{l}1992 \text { and } 1994 \\
\text { respondents }\end{array}$ & 4 \\
\hline 2000 & 64.0 & 1006 & 86.1 & 92.9 & 92.4 & $\begin{array}{l}\text { Face to face and } \\
\text { telephone }\end{array}$ & Yes & No & $\mathrm{n} / \mathrm{a}$ \\
\hline 2004 & 66.1 & 1212 & 88.0 & 95.5 & 92.1 & Face to face & Yes & No & 1 \\
\hline
\end{tabular}

Most of the NES response rates were calculated before the AAPOR response rate standard definitions. The closest is AAPOR RR1 (Luevano, 1994). $\mathrm{n} / \mathrm{a}$ indicates the information about sample replicates was not available from the NES documentation. Retention rate calculated conditional on participation in the pre-election survey. The numerator is the number of participants in the post-election survey. The denominator is the number of respondents in the pre-election survey.

\subsection{Pre-election study benchmark comparisons}

No direct information is available about persons who did not participate in the pre-election survey in all of these years. Yet nonresponse to the post-election survey is a conditional phenomenon, dependent on those who participate in the first wave. Furthermore, estimates that are based on information from the post-election interview such as the proportion of persons who voted are a function of the cumulative nonresponse process from both waves.

To evaluate whether there are changes in the representation of groups in the pre-election survey across time, we compare the sex, race, and age distribution of pre-election survey respondents to the distribution of these characteristics in the population in each year. We use characteristics of the voting age population of US citizens measured in the November Current Population Survey as the benchmark comparison for each election year (US Bureau of the Census, 1965, 1969, 1973, 1978, 1982, 1986, 1989, 1993; Casper and Bass, 1998; Jamieson et al., 2002; Holder, 2006) ${ }^{1}$; information on citizenship is not available for 1964, so we examine the full US population. Benchmark comparisons provide a measure of nonresponse bias on these characteristics, but also reflect measurement and post-survey processing differences between the two surveys (Groves, 2006).

The similarity between the age, race and sex distributions of the NES pre-election respondents to the population distributions is evaluated using chi-square goodness of fit statistics. Chi-square statistics are calculated under an SRS assumption in all years. For 1988 through 2004, complex sample design information in the ANES is available, and Rao-Scott design adjustments are used on the chi-square statistics using PROC SURVEYFREQ in SAS 9.2 for these years. In all but one instance (the race distributions in 1988), the conclusions from the design adjusted chi-square statistics are the same as the conclusions from the SRS chi-square statistics. These analyses treat the CPS data as "true values," measured without sampling error. The CPS has a large sample and is highly precise, with standard errors of these estimates of less than 1\% (US Bureau of the Census, 1965, 1969, 1973, 1978, 1982, 1986, 1989, 1993; Casper and Bass, 1998; Jamieson et al., 2002; Holder, 2006).

\subsection{Measuring survey retention, contact, and cooperation}

Post-election survey retention is measured through a dichotomous variable where ' 1 ' indicates that the pre-election survey respondent participated in the post-election survey and ' 0 ' indicates that they did not, conditional on

1. Voter registration (in some years) and voting (in all years) is measured in the post-election ANES survey and thus is excluded from our comparisons. 
participation in the pre-election survey. The retention rate calculated with this variable corresponds most closely to AAPOR Response Rate 2, conditional on participation in the pre-election survey (AAPOR, 2009).

Survey participation can be separated into contact and cooperation. Some individuals are never contacted by a survey interviewer; others are contacted, but refuse to participate with a survey request (Groves and Couper, 1998). Information on contactability and cooperation is only available from 1988 to 2004. Pre-election survey respondents who were interviewed in the post-election survey or who were contacted, but refused to participate in the post-election survey, are counted as a 'contact.' All other pre-election respondents are counted as a 'non-contact,' permitting calculation of AAPOR Contact Rate 1 (AAPOR, 2009). Cooperation indicates that a contacted person agreed to participate with the survey request. Among those contacted pre-election survey respondents, interviews (partial if included in the data file) are coded as 'cooperators' and non-interviews were coded as 'not cooperators,' corresponding to AAPOR Cooperation Rate 2 (AAPOR, 2009).

\subsection{Estimating changes over time in post-election survey retention, contact, and cooperation}

Logistic regression models predicting retention in the post-election survey $(p)$ using wave one covariates are estimated. The year of the survey ranges from -20 (1964) to +20 (2004), centered at 0 (1984) (Aiken and West, 1991). The base model simply contains a linear and a quadratic term for year:

$$
\operatorname{logit}(p)=\beta_{0}+\beta_{1} \text { year }+\beta_{2} \text { year }^{2}
$$

Interactions for each explanatory variable with the linear and quadratic year terms examine whether post-election survey response rates differed across the years for different groups. For example, to examine whether retention rates for respondents of different ages differed across the years, we tested

$$
\operatorname{logit}(p)=\beta_{0}+\beta_{1} \text { year }+\beta_{2} \text { year }^{2}+\beta_{3} \times \text { Age }+\beta_{4}(\text { Age } \times \text { year })+\beta_{5}\left(\text { Age }^{2} \text { year }^{2}\right)
$$

If $\hat{\beta}_{4}$ and/or $\hat{\beta}_{5}$ are significantly different from zero at an $p<.05$ level, then we conclude that retention rates for different age groups differed systematically over time. ${ }^{2}$ Then, the statistically significant predictors, including the significant interaction terms with time, are combined in a single model examining panel attrition across the 40 years of the ANES:

$$
\operatorname{logit}(p)=\beta_{0}+\beta_{1} \text { year }+\beta_{2} \text { year }^{2}+\sum_{p=1}^{p} \beta_{3 p} X_{p}+\sum_{p=1}^{P} \beta_{4 p}\left(X_{p} \times \text { year }\right)+\sum_{p=1}^{P} \beta_{5 p}\left(X_{p} \times \text { year }^{2}\right)
$$

We removed higher order interactions with time that were not statistically different from zero at a $p<.05$ level in the multivariate model. Given the multiple comparisons, we plot each significant interaction effect to identify whether the results are consistent with our a priori hypotheses. The results presented here show only Model 3, the final multivariate models; results for the bivariate analyses are available from the authors on request.

Beginning in 1988, we are able to disentangle noncontact from refusal nonresponse. We follow the modeling procedures described above, changing the dependent variable to contact and cooperation, given contact. In these models, we test both the linear and quadratic "year" terms. We include both linear and quadratic "year" terms in the contact model, but only the linear "year" term in the cooperation model because the quadratic term was not statistically different from zero at a $p<.05$ level. As before, the interaction term between an independent variable and time was included if its effect was significantly different from zero at a $p<.05$ level. We reestimate the overall retention model, predicting response to the post-election survey, for two time periods - 1964 to 1984 and 1988 to 2004 - with linear "year" terms and a quadratic term in the 1964-1984 analysis; the quadratic term was not statistically different from zero at a $p<.05$ level in the 1988-2004 analysis.

Although the sample design in each year was a complex area probability sample, design weights, cluster and strata variables for analytic purposes are only available for 1988 through 2004, but not for data collected during 1984 and earlier. We examine sensitivity to our modeling decisions for the overall, contact, and cooperation models by including complex survey design adjustments for the years in which these were available (1988 through 2004). ${ }^{3}$ The direction and magnitude of the coefficients estimated in these models were similar to the coefficients estimated in the nondesign adjusted models (see Appendix Table A1). Reductions in statistical significance levels were seen in three of four interactions with time. Since these differences may simply arise because of increased estimated variances in the later years, we report only the analyses that assume a simple random sample for all years.

\subsection{Selecting candidate correlates of changes in retention over time}

To select independent variables, we first identified respondent characteristics that: (1) represented subgroups that experienced substantial social changes, as reviewed above, (2) had been found to predict panel attrition or cross-sectional survey participation, or (3) were central to the survey topic (politics, voting or elections). Then, we examined whether these characteristics were available in each of the 11 administrations of the pre-election survey. Many can-

2. We also estimated models with indicator variables for each year. Results available from authors on request.

3. The ANES recommends accounting for the complex design in analyses intended to generalize to the full population (DeBell and Krosnick, 2009). The early ANES data sets do not contain information to identify analytic strata or clusters (Personal Communication, ANES Staff, January 25, 2011). 

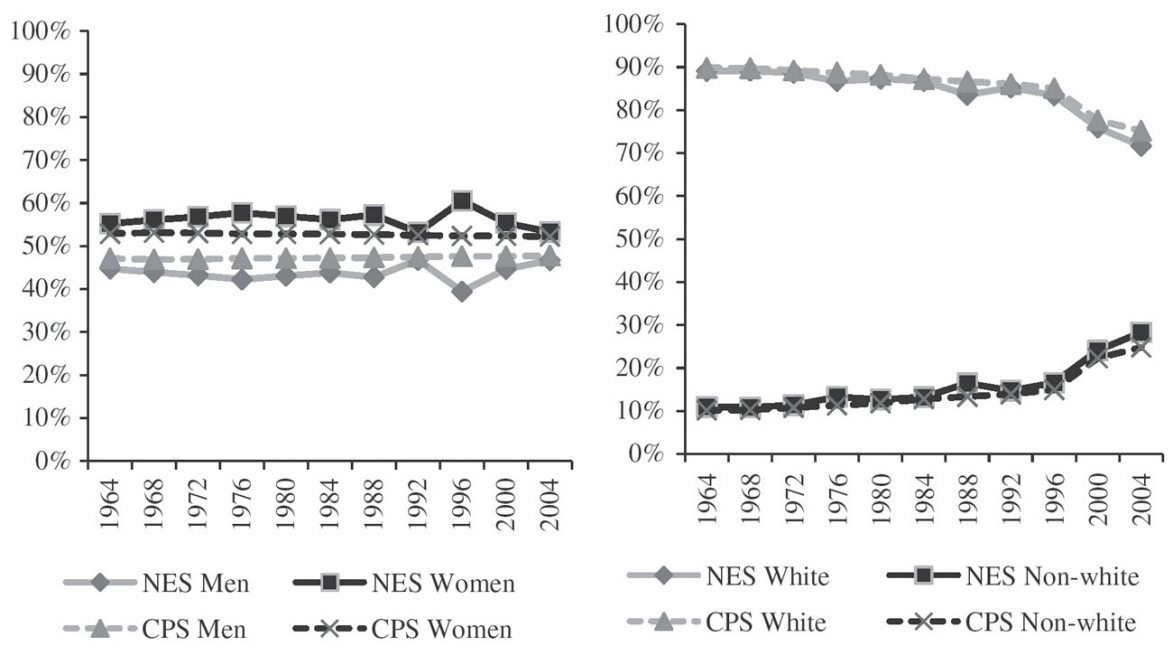

Figure 1. Percent of men, women, whites and non-whites in the American National Election Studies and the Current Population Study, 1964-2004.

didate variables were not available in the pre-election survey in all of the years. As such, 13 available independent variables include demographic variables, socio-economic variables, political opinions and attitudes, political interests, and information about the pre-election survey experience.

Urbanicity (central city, suburban, rural) is the only consistently available geographic variable. Age (entered as a continuous variable, with a mean of 45 years old across the years $(S D=17.5)$ ), sex (male vs. female), education (less than high school graduate, high school graduate, and high school or beyond), marital status (married; single, divorced or separated; or widowed), and race (whites versus non-whites) are included in the models. Income was coded into quartiles within each year, with item nonresponse (don't know or refusal) on the income question left as a separate category.

Four political affiliation and attitude questions are available across the years, including two measures of party identification - party affiliation (Democrat, Independent, Republican and no reported party), and the political party of the candidate for which they intended to vote in the upcoming presidential election (Republican, Democrat, third party candidate, and no intention to vote). Pre-election respondents also reported whether they cared which party wins the presidency (care, don't care, and no response) and their level of interest in political campaigns (very much, somewhat, and not much interest).

Two paradata-derived variables (Couper, 1998) measure the pre-election survey experience: the length of the preelection interview in minutes and the number of weeks before the election during which the pre-election interview occurred. Both are included as continuous variables. The average length of interview across the years is about 74 min $(S D=22.6)$; the average number of weeks before the election is 4.7 weeks $(S D=2.4)$.

Missing data was present in all but two (gender and urbanicity) predictors. Where missing data rates are less than $2 \%$ of the total case count in each year (age, education, marital status, race, $n<20$ in each year), we assign the mean (age, length of interview) or modal (for categorical predictors) value for that variable. Where missing data rates are greater than $2 \%$ of the total case count in each year, we included a missing data category in the model. Missing data on variables such as income previously has been shown to predict panel attrition (Loosveldt et al., 2002). Although a more sophisticated imputation procedure could be conducted, an examination of the analyses with and without this simple imputation showed few differences in conclusions due to the small sample sizes for the imputed cases.

\section{Results}

We start with the benchmark comparisons between the pre-election survey respondents and the benchmark Current Population Survey data. We then present results from the modeling of post-election survey retention rates. Modeling results are divided into characteristics for which we found changes in retention rates over time and those whose retention rates stayed relatively the same. We examine models for the overall time period (1964-2004) and then models separately for 20 year segments (1964-1984 and 1988-2004). Changes within and between these two periods will be discussed in relation to the changes seen over the entire 40 year span. To ease interpretation, we provide graphs for interpreting statistically significant $(p<.05)$ interaction effects.

\subsection{Benchmark comparisons}

Figure 1 compares the sex and race distribution for the ANES pre-election respondents (the solid lines) and the population distribution from the CPS (the dashed lines). In the left panel of Figure 1, we see that women are systematically overrepresented and men are systematically underrepresented in each year, although there is variability across the years in the magnitude of the difference. These findings are consistent with previous ANES benchmark compari- 


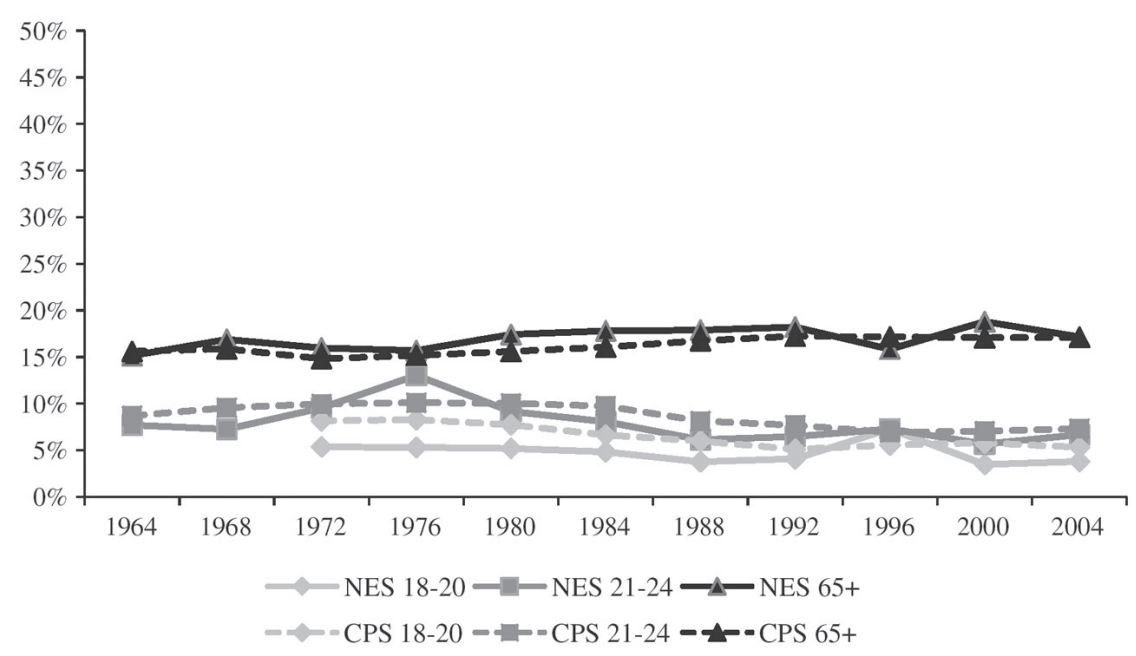

Figure 2. Percent of 18-20, 21-24, and 65+ year olds in the American National Election Studies and the Current Population Study, 1964-2004.

sons of surveys conducted during the 1980s (Brehm, 1987). Using chi-square goodness of fit statistics, the sex distribution in the pre-election survey respondents is statistically different $\left(\chi^{2}>5.5,1 \mathrm{df}, p<.05\right)$ from the population distribution in all years but $1964\left(\chi^{2}=3.49,1 \mathrm{df}, p=.06\right), 1992\left(\chi^{2}=0.22,1 \mathrm{df}, p=.64\right), 2000\left(\chi^{2}=3.55,1 \mathrm{df}, p=.06\right)$ and 2004 $\left(\chi^{2}=0.59,1 \mathrm{df}, p=.59\right)$. The average absolute difference of the percent of men between the survey and population estimates is $3.6 \%(S D=0.9 \%)$ from 1964 to 1984 and 3.5\% (SD=3.1\%) from 1988 to 2004. The differences between the preelection survey and population distributions are much more variable after 1984.

In the right panel of Figure 1, we see that the proportion of white (white, non-Hispanic in 2000 and 2004) and nonwhite pre-election survey respondents mirrors the population distribution closely. Non-whites are slightly overrepresented in all years of the survey, but significant differences are found between the two groups only in $1976\left(x^{2}=4.83\right.$, $1 \mathrm{df}, p=.02)$ and $2004\left(\chi^{2}=7.96,1 \mathrm{df}, p=.005\right)$. The 2004 result could be due to differences in how race was coded in the check-all-that-apply race question across the two surveys. ${ }^{4}$ The average absolute difference between the percent of whites is $0.9 \%$ ( $S D=0.5 \%$ ) from 1964 to 1984 , and 2.2\% from 1988 to $2004(S D=1.1 \%)$. There is a slight increase in representation of non-whites relative to whites in the later years, and, as with the sex distribution, greater variability in the absolute differences between the survey and population distribution in the later years.

We examined seven age categories in each study - 18 to 20 year olds (excluded from 1964 and 1968 as voting age was 21), 21-24, 25-34, 35-44, 45-54, 55-64, and 65 years and above. The age distributions were statistically significantly different $(p<.05)$ in all years but $1964\left(\chi^{2}=5.77,5 \mathrm{df}, p=.33\right)$ and $1996\left(\chi^{2}=3.03,6 \mathrm{df}, p=.80\right)$. Figure 2 displays the percent of the ANES pre-election respondent pool and US population in the two youngest age groups (18-20 and 21-34) and the oldest age group (65+). The ANES pre-election respondent pool under represents the youngest age groups in almost all of the years, with an absolute difference of about $2 \%$ points for the 18-20 year olds (average of $2.5 \%$ from 1972 to $1984 ; 1.8 \%$ from 1988 to 2004 ) and about 1\% point for the $21-24$ year olds (average $1.5 \%$ from 1964 to $1984 ; 1.1 \%$ from 1988 to 2004). The average absolute difference between the ANES distribution and the population distribution and the standard deviation of the absolute difference fell for five of the seven age groups (age 35-44 and 55-64 are the exceptions) between these two time periods, indicating greater alignment of the survey and population age distributions in the later years.

In sum, there is evidence that women are significantly overrepresented in the pre-election survey relative to their population distribution, but that the overrepresentation does not systematically change over time. Non-whites are slightly overrepresented in each year, and the overrepresentation increases in the later years of the survey. Young adults are underrepresented in almost every year of the study, with a slight weakening of the underrepresentation over the years.

\subsection{Retention rate trends over time}

The retention rate in the post-election ANES decreased from $91.8 \%$ in 1964 to $79.4 \%$ in 1976, but increased to $87.2 \%$ in 1980, maintaining a relatively constant rate between $85 \%$ and $90 \%$ from 1980 to 2004 (Table 1). In contrast to investigations of cross-sectional response rates, there is no systematic linear decline in post-election survey retention over this time period. In fact, the linear year term is not statistically different from zero (beta $=-0.014, p=0.12$ ), but the quadratic year term is positive and significant (beta $=0.0019, p<.0001$ ), reflecting the decline and then increase in retention rates. We also see this when we look at retention declining and then increasing from 1964 to 1984 (quadratic term beta $=0.013, p<0.0001$ ) and then no statistically significant change from 1988 to 2004 (beta $=-0.0028, p=0.82$ ).

4. Under an SRS assumption, statistical differences are found between the two race distributions in $1988\left(\chi^{2}=16.57,1 \mathrm{df}, p<.0001\right)$, but the statistically significant differences were eliminated once the complex survey design was taken into account $(\chi 2=1.4,1 \mathrm{df}$, $p=0.20)$. 

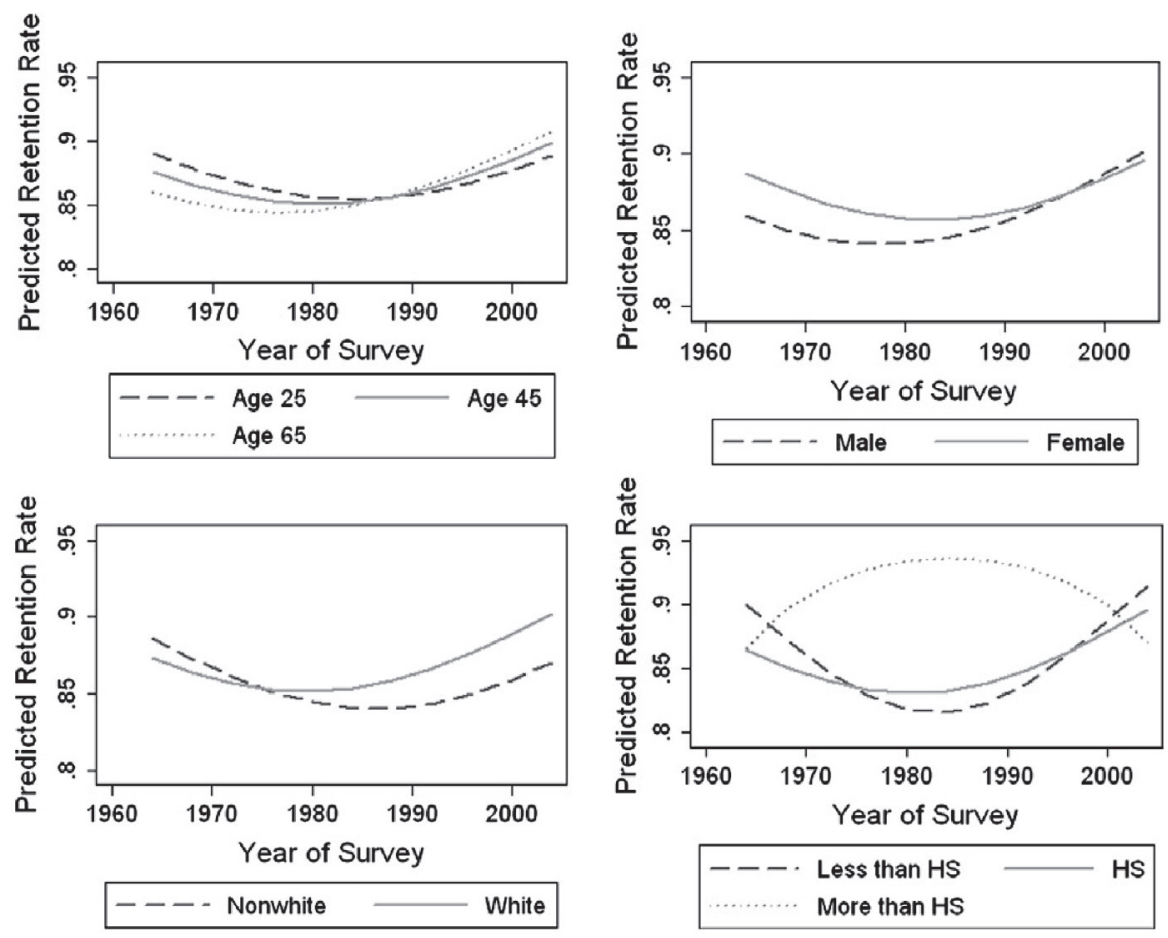

Figure 3. Predicted post-election survey retention rates for age, sex, race and education groups, 1964-2004, American National Election Studies.

\subsubsection{Characteristics with changes in retention rates over time}

As hypothesized, retention rates changed differentially across age, gender, education, and race groups from 1964 to 2004. Although younger pre-election survey respondents were more likely to participate in the post-election studies during the early years (1964-1984) (Figure 3, beta $=-0.004, p<.05$ ), they were equally likely to participate in the post-election studies during the later years (e.g., 1988-2004) (beta $=0.0035, p=0.22$ ). This shift corresponds to a significant age * year interaction term (Table 2, beta $=0.0003, p<.05)$ in the 1964-2004 model.

Although women are slightly more likely to participate in the post-election study than men, the gap in retention rates between the two groups declined over time from 1964 to 2004 (year * female beta $=-0.0082, p=.045$, see Figure 3). From 1964 to 1984, women's retention rates are significantly higher than men's (beta $=0.175, p<.01$ ), but the retention rates are statistically identical after 1984 (beta $=0.001$, n.s.).

Retention rates for whites grew relative to those for nonwhites between 1964 to 2004 (white * year beta = 0.011, $p<.05)$. During the 1964-1984 time period, whites and non-whites have very similar retention rates, (beta $=-0.077$, n.s.). After 1984, however, whites have higher retention rates than nonwhites (beta $=0.306, p<.01$ ).

The difference in retention rates across education groups changed significantly over the time period, although the pattern is complex (see Figure 3). Persons with more than a high school degree tended to have the highest retention rates over the entire period. Persons with less than a high school degree or at most a high school degree had very similar retention rates over the period, falling and then rising over the 40 year span. The decline was more gradual for those with a high school degree than for those with less than a high school degree. These changes correspond to statistically significant education * year and education * year ${ }^{2}$ interaction terms in the 1964 to 2004 model, with a statistically significant interaction education * year $(p=0.003)$ in the 1964-1984 model, and no statistically significant changes over time from 1988 to 2004.

Three characteristics - urbanicity, party identification, and the length of time that had elapsed between the first interview and the election date - showed statistically significant changes over one of the shorter time periods, but not over the longer time period. There was not a detectable systematic change in retention rates across urbanicity groups over the 40 year time span, although differences were observed between 1988 and 2004. Consistent with previous research (Steeh, 1981; Steeh et al., 2001), outlying and rural areas had the highest retention rate, followed by suburban areas, and then urban areas. Retention rates in suburban areas and outlying areas declined in later years, such that there is no noticeable difference across urbanicity areas in retention rates by 2000.

From 1964 to 1984, Republicans were significantly more likely to participate than Democrats, with the gap increasing and then decreasing during these years (reflected in a significant interaction effect between party affiliation and both the linear and quadratic year terms). From 1988 to 2004, the gap in retention rates between Republicans and Democrats grew, and Republicans were even more likely (Republican * year beta $=0.038, p<.01$ ) to participate in the post-election study than the Democrats or independents. Differences were also seen over time in those who did not identify with a party; however this group was very small in size. 
Table 2. Coefficients and standard errors from three logistic regression models predicting retention, 1964-2004, 19641984, and 1988-2004, American National Election Studies.

\begin{tabular}{|c|c|c|c|c|c|c|c|c|c|}
\hline \multirow[b]{3}{*}{ Intercept } & \multicolumn{3}{|c|}{ 1964-2004 } & \multicolumn{3}{|c|}{ 1964-1984 } & \multicolumn{3}{|c|}{ 1988-2004 } \\
\hline & \multirow{2}{*}{$\begin{array}{r}\text { Beta } \\
0.960\end{array}$} & \multicolumn{2}{|c|}{$S E$} & Beta & \multicolumn{2}{|r|}{$S E$} & \multicolumn{2}{|c|}{ Beta } & \multirow{2}{*}{$\begin{array}{r}S E \\
0.304\end{array}$} \\
\hline & & $* * * *$ & 0.169 & 1.700 & $* * * *$ & 0.259 & 1.092 & *** & \\
\hline Year & -0.014 & & 0.009 & 0.218 & $* * * *$ & 0.038 & 0.003 & & 0.013 \\
\hline Year $^{2}$ & 0.002 & $* * * *$ & 0.0004 & 0.013 & $* * * *$ & 0.002 & - & & - \\
\hline Age & -0.001 & & 0.001 & -0.004 & * & 0.002 & 0.003 & & 0.003 \\
\hline Year * age & 0.0003 & * & 0.0001 & - & & - & - & & - \\
\hline Female & 0.096 & & 0.049 & 0.175 & * * & 0.060 & 0.001 & & 0.084 \\
\hline Year * female & -0.008 & * & 0.004 & - & & - & - & & - \\
\hline High school education & 0.119 & & 0.091 & 0.167 & & 0.148 & 0.026 & & 0.124 \\
\hline More than high school education & 0.484 & $* * * *$ & 0.085 & 0.482 & $* * *$ & 0.126 & 0.318 & * & 0.130 \\
\hline Year * high school education & 0.003 & & 0.006 & 0.033 & ** & 0.012 & - & & - \\
\hline Year * more than high school education & 0.001 & & 0.006 & 0.034 & ** & 0.011 & - & & - \\
\hline Year $^{2} *$ high school education & -0.001 & ** & 0.0005 & - & & - & - & & - \\
\hline Year $^{2} *$ more than high school educ. & -0.002 & $* * * *$ & 0.0005 & - & & - & - & & - \\
\hline White & 0.099 & & 0.068 & -0.077 & & 0.093 & 0.306 & ** & 0.102 \\
\hline Year * white & 0.011 & * & 0.005 & - & & - & - & & - \\
\hline Suburbs & 0.213 & $* * *$ & 0.059 & 0.245 & $* * *$ & 0.075 & 0.404 & * & 0.195 \\
\hline Outlying and rural areas & 0.350 & $* * * *$ & 0.059 & 0.369 & $* * * *$ & 0.073 & 0.944 & $* * * *$ & 0.212 \\
\hline Suburbs * year & - & & - & - & & - & -0.028 & & 0.016 \\
\hline Outlying and rural areas * year & - & & - & - & & - & -0.056 & $* * *$ & 0.016 \\
\hline Income $=2$ nd quartile & -0.012 & & 0.071 & -0.038 & & 0.089 & 0.052 & & 0.124 \\
\hline Income $=3$ rd quartile & 0.078 & & 0.078 & 0.095 & & 0.098 & 0.013 & & 0.133 \\
\hline Income $=4$ th quartile & -0.039 & & 0.082 & -0.060 & & 0.102 & 0.009 & & 0.144 \\
\hline Income $=$ missing & -0.600 & $* * * *$ & 0.084 & -0.736 & $* * * *$ & 0.109 & -0.500 & $* * *$ & 0.139 \\
\hline Single, divorced, or separated & -0.080 & & 0.058 & -0.111 & & 0.075 & -0.023 & & 0.096 \\
\hline Widowed & -0.022 & & 0.087 & -0.006 & & 0.103 & -0.019 & & 0.165 \\
\hline Independent & -0.103 & & 0.074 & 0.0058 & & 0.201 & -0.259 & & 0.256 \\
\hline Republicans & 0.248 & *** & 0.065 & 0.176 & & 0.151 & -0.298 & & 0.193 \\
\hline Party ID = missing & -0.228 & & 0.143 & -0.623 & * & 0.301 & -1.658 & & 0.480 \\
\hline Independent * year & - & & - & -0.024 & & 0.045 & 0.014 & & 0.020 \\
\hline Republicans * year & - & & - & -0.074 & * & 0.034 & 0.038 & ** & 0.014 \\
\hline Party ID $=$ missing $*$ year & - & & - & -0.220 & ** & 0.081 & 0.147 & $* *$ & 0.051 \\
\hline Independent * year ${ }^{2}$ & - & & - & -0.0027 & & 0.0023 & - & & - \\
\hline Republicans * year $^{2}$ & - & & - & -0.0046 & * * & 0.002 & - & & - \\
\hline Party ID = Missing * Year $^{2}$ & - & & - & -0.013 & * * & 0.004 & - & & - \\
\hline Will vote for Republican & -0.073 & & 0.068 & -0.001 & & 0.085 & -0.040 & & 0.123 \\
\hline Will vote for third party candidate & -0.218 & & 0.13 & -0.124 & & 0.162 & -0.191 & & 0.223 \\
\hline Will not vote or DK who will vote for & -0.276 & $* * * *$ & 0.066 & -0.233 & * * & 0.082 & -0.098 & & 0.125 \\
\hline Do not care who wins President & 0.017 & & 0.054 & 0.078 & & 0.066 & -0.111 & & 0.101 \\
\hline DK care for who wins President & -0.150 & & 0.129 & 0.0005 & & 0.145 & -0.601 & & 0.311 \\
\hline Interest in campaigns $=$ somewhat & -0.134 & * & 0.059 & -0.071 & & 0.073 & -0.265 & ** & 0.102 \\
\hline Interest in campaigns $=$ not a lot & -0.399 & $* * * *$ & 0.069 & -0.431 & $* * * *$ & 0.084 & -0.365 & ** & 0.129 \\
\hline Length of interview in minutes & 0.005 & $* * * *$ & 0.006 & 0.001 & $* * * *$ & 0.001 & 0.004 & * & 0.002 \\
\hline Weeks before the election & 0.037 & $* * *$ & 0.009 & -0.024 & & 0.026 & 0.031 & * & 0.015 \\
\hline Weeks before the election * year & - & & - & -0.023 & $* * *$ & 0.007 & - & & - \\
\hline Weeks before the election * year ${ }^{2}$ & - & & - & -0.001 & ** & 0.0004 & - & & - \\
\hline Missing demographic variables & -0.473 & ** & 0.161 & -0.092 & & 0.239 & -0.884 & $* * * *$ & 0.224 \\
\hline Likelihood ratio chi-square & 456.67 & $* * * *$ & & 428.43 & $* * * *$ & & 165.71 & $* * * *$ & \\
\hline Degrees of freedom & 35 & & & 38 & & & 32 & & \\
\hline Pseudo- $R^{2}$ & $3.5 \%$ & & & $4.9 \%$ & & & $3.8 \%$ & & \\
\hline Percent concordant predictions & $62.9 \%$ & & & $65.4 \%$ & & & $63.8 \%$ & & \\
\hline
\end{tabular}

${ }^{*} p<.05 ; * * p<.01 ; * * * p<.001 ; * * * * p<.0001$

\subsubsection{Characteristics with no changes in retention rates over time}

There are no clear differences over time in the association between attrition rates and variables defined by income, marital status, having interest in campaigns, caring who will be the president, the length of the pre-election interview, or item nonresponse on the demographic variables. There is no difference over time in the association of panel retention with marital status or with caring who wins the presidential election in the multivariate models, although differences in attrition rates over time exist in the bivariate analyses for both variables. Item nonresponse on either the income question (beta $=-.60, p<.0001$ ) or at least one demographic question (beta $=-0.473, p<.01$ ) negatively predicts post-election study participation. Interest in following the presidential campaign positively predicts participation in the post-election survey compared to somewhat (beta $=-0.134, p<.05)$ or not interested reports $($ beta $=-0.399$, 
Table 3. Combined model predicting contactability and cooperation in the American National Election Studies postelection survey, 1988-2004.

\begin{tabular}{|c|c|c|c|c|c|c|}
\hline & \multicolumn{3}{|c|}{ Contact } & \multicolumn{3}{|c|}{ Cooperation } \\
\hline & Beta & & $S E$ & Beta & & $S E$ \\
\hline Intercept & 3.744 & $* *$ & 0.578 & 1.594 & $* * * *$ & 0.374 \\
\hline Year & -0.341 & $* * * *$ & 0.069 & 0.034 & * & 0.017 \\
\hline Year $^{2}$ & 0.011 & $* * * *$ & 0.003 & - & & - \\
\hline Age & 0.009 & & 0.005 & 0.0005 & & 0.003 \\
\hline Female & 0.457 & $* * *$ & 0.132 & -0.225 & * & 0.104 \\
\hline High school education & 0.192 & & 0.194 & -0.033 & & 0.150 \\
\hline More than high school education & 0.377 & & 0.200 & 0.317 & * & 0.159 \\
\hline Suburbs & 0.148 & & 0.159 & 0.593 & ** & 0.226 \\
\hline Outlying and rural areas & 0.149 & & 0.164 & 1.152 & $* * * *$ & 0.249 \\
\hline Suburbs * year & - & & - & -0.052 & $* *$ & 0.020 \\
\hline Outlying and rural areas * year & - & & - & -0.075 & $* * *$ & 0.021 \\
\hline Income $=2$ nd quartile & 0.156 & & 0.186 & -0.035 & & 0.156 \\
\hline Income $=3$ rd quartile & 0.356 & & 0.210 & -0.205 & & 0.165 \\
\hline Income $=4$ th quartile & 0.208 & & 0.225 & -0.153 & & 0.179 \\
\hline Income $=$ missing & -0.226 & & 0.210 & -0.681 & $* * * *$ & 0.170 \\
\hline Single, divorced, or separated & -0.283 & & 0.150 & 0.118 & & 0.118 \\
\hline Widowed & -0.378 & & 0.263 & 0.158 & & 0.201 \\
\hline White & 0.514 & $* * *$ & 0.152 & 0.209 & & 0.129 \\
\hline Independent & -0.0002 & & 0.214 & -0.435 & & 0.296 \\
\hline Republicans & 0.062 & & 0.184 & -0.400 & & 0.229 \\
\hline Party ID = missing & 0.430 & & 0.542 & -1.981 & $* * *$ & 0.519 \\
\hline Independent * year & - & & - & 0.027 & & 0.025 \\
\hline Republicans * year & - & & - & 0.054 & $* *$ & 0.018 \\
\hline Party ID = missing * year & - & & - & 0.155 & $* *$ & 0.058 \\
\hline Will vote for Republican & -0.097 & & 0.192 & -0.056 & & 0.151 \\
\hline Will vote for third party candidate & -0.032 & & 0.329 & -0.208 & & 0.284 \\
\hline Will not vote or DK who will vote for & 0.087 & & 0.199 & -0.158 & & 0.151 \\
\hline Do not care who wins President & -0.381 & * & 0.157 & 0.055 & & 0.125 \\
\hline DK care for who wins President & -0.395 & & 0.610 & -0.621 & & 0.342 \\
\hline Interest in campaigns $=$ somewhat & -0.222 & & 0.160 & -0.253 & * & 0.126 \\
\hline Interest in campaigns $=$ not a lot & -0.063 & & 0.208 & -0.451 & ** & 0.156 \\
\hline Length of interview in minutes & -0.001 & & 0.003 & 0.007 & * & 0.003 \\
\hline Weeks before the election for Interview & -0.017 & $* * *$ & 0.051 & 0.006 & & 0.018 \\
\hline Weeks before the election for Interview * year & 0.0079 & * & 0.004 & - & & - \\
\hline Missing demographic variables & -1.178 & $* * *$ & 0.307 & -0.719 & ** & 0.278 \\
\hline Chi-square & 135.21 & $* * * *$ & & 143.36 & $* * * *$ & \\
\hline Df 1 & 29 & & & 32 & & \\
\hline Psuedo- $R^{2}$ & $6.2 \%$ & & & $4.4 \%$ & & \\
\hline Percent concordant predictions & $68.0 \%$ & & & $65.3 \%$ & & \\
\hline
\end{tabular}

${ }^{*} p<.05 ;{ }^{*} p<.01 ; * * * p<.001 ; * * * * p<.0001$

$p<.0001$ ) in following campaigns. As expected, the length of interview is positively associated with retention in the post-election survey (beta $=0.005, p<.0001$ ), as are the number of weeks before the election during which the preelection interview occurred (beta $=0.037, p<.001$ ).

\subsection{Predictors of contact and cooperation in the ANES}

The post-election survey contact rates significantly decrease between 1988 and 2004 (year beta $=-0.341, p<.0001$; year ${ }^{2}$ beta $\left.=0.011, p<.0001\right)$, while the cooperation rates significantly increase (beta $\left.=0.034, p<.05\right)$ over the same time period. Thus, although retention rates did not systematically decline, contact rates did. This decline is counteracted by a rise in cooperation rates (see Table 3).

\subsubsection{Characteristics that change in contact and cooperation rates over time}

Few of the predictors in the model are statistically significantly related to contactability. Only one (the number of weeks before the election that the pre-election interview occurred) showed a relationship whose magnitude changes over time, such that contact rates rose (weeks * year beta $=0.0079, p<.05$ ) for those interviewed earlier in the preelection field period (e.g., higher numbers of weeks before the election) between 1988 and 2004. This is likely due to changes in how the sample was released to the field in the 2000 and 2004 pre-election survey data collections.

The only characteristics that change in their relationship with cooperation between 1988 and 2004 are urbanicity and party identification. Cooperation rates for suburban (year * suburb beta $=-0.052, p<, 01$ ) and rural (year * rural 
Table 4. Group most likely to participate, be contacted, and cooperate from 1988 to 2004.

\begin{tabular}{|c|c|c|c|}
\hline & Retention & Contact & Cooperation \\
\hline Age & - & - & - \\
\hline Gender & - & Females & Males \\
\hline Education & More than HS & - & More than HS \\
\hline Income & Income reporters & - & Income reporters \\
\hline Marital status & - & - & - \\
\hline Race & White & White & - \\
\hline Partisan vote intentions & - & - & - \\
\hline Interested in campaigns & Very much & Very much & Very much \\
\hline Care who wins & - & Care & - \\
\hline Length of interview & Longer & - & Longer \\
\hline Weeks until the election & Earlier & Earlier & - \\
\hline Item nonresponse on demographic variables & Reporters & Reporters & Reporters \\
\hline
\end{tabular}

beta $=-0.075, p<.001)$ residents fell over this time period, while cooperation rates for urban residents rose from 1988 to 2004 . Thus, the change observed in overall retention rates across urbanicity groups for 1988-2004 is driven by declining cooperation rates in suburban and rural areas, rather than increased difficulty in making contact in any of these areas. Cooperation rates across party affiliation changed significantly between 1988 and 2004. Cooperation rates for Republicans grew faster than those for Democrats (Republican beta * year $=0.054, p<.01$ ), such that Republicans had the highest cooperation rates in most years, after adjusting for the other characteristics in the model, and the gap increased slightly over time. Independents had the lowest cooperation rates, although they were not statistically different from Democrats.

\subsubsection{Characteristics that do not change in contact and cooperation rates over time}

The remaining variables had a consistent relationship with contactability and cooperation between 1988 and 2004 , as summarized in Table 4. Among the demographic variables, women were more likely to be contacted (beta $=0.457$, $p<.001$ ), but men were more likely to cooperate (beta $=-0.225, p<0.05$ ). These counteracting effects resulted in no net effect of sex on overall retention during this time period. Persons with more than a high school education were more likely to cooperate than those with less than a high school education, but there was no difference in contactability across education groups. Respondents with item nonresponse on income (beta $=-.68, p<.0001$ ) or demographic variables (beta $=-0.719, p<.01$ ) are significantly less likely to cooperate than respondents who reported an income or answers to the demographics. There was no relationship between income and contactability, although item nonresponse on demographic variables was a strong indicator of noncontact in the post-election study (beta $=-1.178$, $p<.001)$.

There are no clear differences across partisan voting intentions, although caring and being interested in politics are related to post-election survey contact and cooperation. People who do not care who wins the Presidential race are less likely to be contacted than those who do care (beta $=-0.381, p<0.05$ ), but there is no relationship with cooperation. Being interested in following campaigns is a strong predictor of cooperation, with those who report somewhat (beta $=-0.253, p<.05$ ) or not a lot (beta $=-0.451, p<.01$ ) much less likely to cooperate, although there is no relationship with contactability.

The pre-election survey experience characteristics are differentially related to contact and cooperation. The length of the pre-election interview was significantly and positively related to cooperation in the post-election survey (beta $=0.007, p<.05$ ), but not related to contacting the sampled household. The number of weeks before the election during which the pre-election interview occurred predicts contactability, with the strength of the relationship changing over time, but is not related to cooperation.

\section{Discussion and conclusion}

The relationship between characteristics of people and survey participation today is not necessarily the same as the relationship between those characteristics and survey participation many years ago. We examined whether predictors of panel attrition changed magnitude or direction over a 40 year time period encompassing eleven administrations of the American National Election Studies, and predictors of contactability and cooperation over a 16 year time period. Based on cross-sectional literature, we hypothesized differences in response rates for groups that had experienced large social shifts (age, race, sex, education groups) and urbanicity groups. We showed that older respondents and white respondents have higher probabilities of participating today than a few decades ago. Interestingly, differences between the sexes and education groups appear to be diminishing on survey participation, at least in wave two of an election study. We also suspected that there would be changes in participation that reflected differences in the political climate. This is what we found. Yet, although there have been substantial changes in the nature of the survey request and in the time demands and views of surveys across the years, most characteristics had consistent effects across the years on the probability of participating, being contacted, or cooperating in the post-election study. This is consistent with what we predicted - the largest shifts in response rates would occur for subgroups that have experienced large social and political changes over the years. 
The changes observed in retention rates across age groups across time could reflect a cohort effect (as a person who was 25 in 1964 was 45 in 1984 and 65 in 2004). To our knowledge, there has been no period-cohort analysis of survey participation rates. The data contain persons born between 1869 and 1986. Preliminary analyses (not shown) examining both age and 10 year birth cohorts indicate that there may be differences in retention and change in retention rates across birth cohorts. Given small sample sizes of some cohorts, it is difficult to obtain reliable estimates for some of the model parameters.

Why does it matter if there are changes in retention rates over time? Any survey estimate is at risk of being biased by nonresponse. Differential response rates over important subgroups may translate to nonresponse bias on key survey estimates related to those subgroups (Groves et al., 2008). Furthermore, many social scientists compare studies conducted today to those conducted in the past to examine societal changes. If the characteristics of persons who participate in surveys change over time, then conclusions about societal changes will be confounded with differential nonresponse bias. One of the most important functions of election studies in particular is to understand political attitudes, voter turnout and partisan choice. If there are differential changes in response rates for important subgroups over these years, then estimates of who votes and who does not vote over time will be affected.

Although there were dramatic shifts in the political and social climate over the 40 years examined here, there was not a clear trend for persons who supported the winner to be the most likely group to participate in the post-election survey. In general, post-election retention rates for Republicans grew during the late 1980s through 2004 relative to those for Democrats or Independents; this growth was driven by higher cooperation rates and held in multivariate models. This finding may reflect changes in the political climate from 1988 to 2004 (from the election of George H.W. Bush to Bill Clinton to George W. Bush). The results from this paper suggest that higher estimated levels of reported votes for the Republican candidate than observed in the actual election may come from higher participation rates for these persons in the post-election survey, not solely from misreports of voting (Presser et al., 1990; Traugott and Katosh, 1979). Recent work has questioned this measurement error hypothesis, asking whether errors in estimates of voter turnout are due to nonresponse error rather than misreporting (Burden, 2000; McDonald, 2003).

The benchmark comparisons and the retention analyses provide different insights into survey nonresponse. Women were overrepresented in the first wave of the ANES according to the benchmark comparisons; and women were also more likely to be retained in the post-election survey, with an attenuation of the difference between men and women over time. Thus, both analyses provide evidence that women are more likely to participate than men in the ANES in both waves; nonresponse to the post-election survey exacerbates women's overrepresentation in the study. The benchmark comparisons indicate higher representation of nonwhites in the pre-election survey with greater representation during later years, but the retention analyses indicate that nonwhites are more likely to attrite than whites, with probabilities of retention decreasing over time. Thus, although both analyses provide evidence of differences in participation probabilities over for whites and nonwhites, the overrepresentation of nonwhites in the pre-election survey is somewhat negated through attrition. Finally, the benchmark comparisons indicate an attenuation of the differences in the age distribution between survey respondents and the population, but not a clear shift in participation rates for any one group. The post-election survey retention analyses indicate a shift over time in retention rates across age groups, somewhat different from the benchmark comparisons. In general, these two analyses provide evidence that nonresponse rates, and thus representation of important subgroups in sample surveys, are changing over time. The differences between the aggregate benchmark comparisons and the micro-level retention analyses could be due to different mechanisms for first and second wave unit nonresponse (e.g., Lepkowski and Couper, 2002), measurement differences across the two surveys, or differences inherent to alternative methods of studying nonresponse bias (e.g., Groves, 2006; Groves and Peytcheva, 2008).

As with any study, this study has limitations. First, all of the subjects in this study are prior survey respondents. However, this weakness is also a strength - we have extensive information on persons from their first wave interview to use as predictors. This is typically not available in cross-sectional studies. Second, an election study is a particular type of study, housed in the political climate of the time with a topic that may be especially attractive to certain persons. Yet the ANES is a frequently used dataset for many social scientists. Third, the analyses do not contain the most recent administration of the ANES. Given the substantial changes in the administration of this survey in 2008, this limitation seems necessary, and is counterbalanced by the length of the time trend. Finally, the length of time between the two waves is only a few months and may not reflect panel studies with longer times between the waves. Although some studies have at least 1 year between waves, this short time increases the likelihood that attitudes measured at time one reflect attitudes at time two.

To our knowledge, no previous study has examined shifts in survey response rates for important subgroups over time. Variation in response rates for subgroups is an important indicator of survey nonresponse bias (Groves et al., 2008). Thus, these changes in response rates also indicate a changing risk of nonresponse bias on key estimates over time. Whether these findings translate to other studies or other survey topics is unknowable from these data. Yet the theory-driven hypotheses that the groups with the most substantial social changes would have the largest shifts over time in response rates were supported, suggesting that the findings are more generally applicable.

Acknowledgments - An earlier version of this paper was presented at the American Association for Public Opinion Research, New Orleans, May 15, 2008. Any opinions, findings and conclusions or recommendations expressed in these materials are those of the authors and do not necessarily reflect the views of the funding organizations for the American National Election Studies. 


\section{Appendix A}

Table A1. Combined model predicting retention, contactability and cooperation in the American National Election Studies Post-Election Survey, 1988-2004, design adjusted analyses.

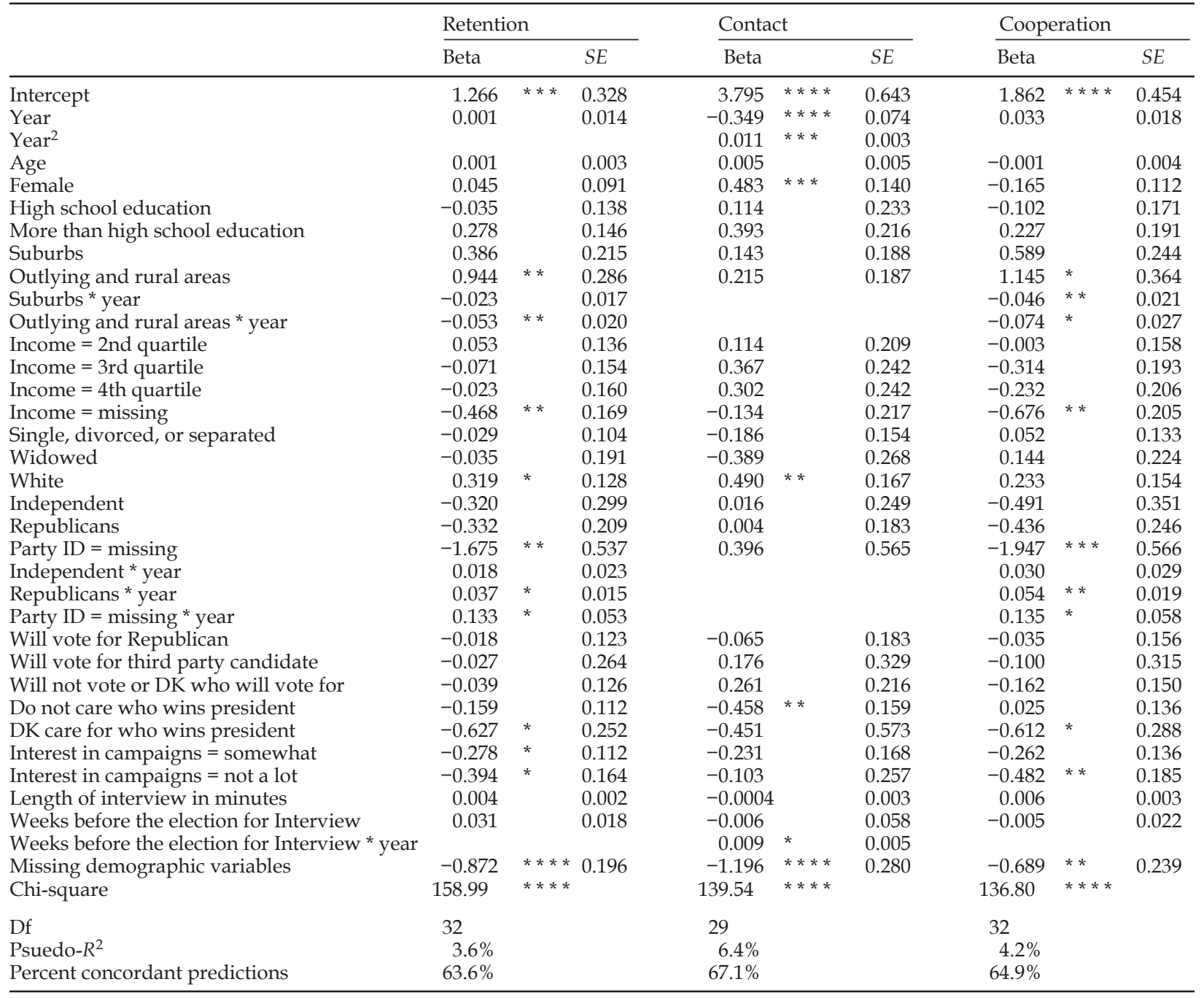

${ }^{*} p<.05 ;{ }^{*} p<.01 ; * * * p<.001 ; * * * * p<.0001$

\section{References}

AAPOR, 2009. Standard Definitions: Final Dispositions of Case Codes and Outcome Rates for Surveys, sixth ed. The American Association for Public Opinion Research.

Agency for Healthcare Research and Quality, 2008. MEPS-HC Response Rates by Panel.

Aiken, L.S., West, S.G., 1991. Multiple Regression: Testing and Interpreting Interactions. Sage Publications, Newbury Park.

Alwin, D.F., McCammon, R.J., 2003. Generations, cohorts and social change. In: Mortimer, J.T., Shanahan, M.J. (Eds.), Handbook of the Life Course. Kluwer Academic/Plenum Publishers, New York, pp. 23-49.

American National Election Studies, 2004. The 2004 National Election Study. University of Michigan, Center for Political Studies, Ann Arbor, MI, pp. dataset.

American National Election Studies, 2008. Other Election Studies. Stanford University and the University of Michigan, with Funding by the National Science Foundation.

Aneshensel, C.S., Becerra, R.M., Fielder, E.P., Schuller, R.H., 1989. Participation of Mexican American female adolescents in a longitudinal panel survey. Public Opinion Quarterly 53, 548-562.

Atrostic, B.K., Bates, N., Burt, G., Silberstein, A., 2001. Nonresponse in US government household surveys: consistent measures, recent trends, and new insights. Journal of Official Statistics 17, 209-226.

Bethlehem, J., 2002. Weighting nonresponse adjustments based on auxiliary information. In: Groves, R.M., Dillman, D.A., Eltinge, J.L., Little, R.J.A. (Eds.), Survey Nonresponse. John Wiley \& Sons, Inc., New York (Chapter 18). 
Blau, F.D., 1998. Trends in the well-being of American women, 1970-1995. Journal of Economic Literature 36, 112-165.

Bogen, K., The effect of questionnaire length on response rates - a review of the literature. In: Proceedings of the Survey Research Methods Section. American Statistical Association, 1996, pp. 1020-1025.

Brehm, J. 1987. Who's Missing? An analysis of non-response and undercoverage in the 1986 national election studies postelection survey. Working paper No. 10, Ann Arbor.

Brehm, J., 1993. The Phantom Respondents: Opinion Surveys and Political Representation. The University of Michigan Press, Ann Arbor, MI.

Burden, B.C., 2000. Voter turnout and the national election studies. Political Analysis 8, 389-398.

Burkam, D.T., Lee, V.E., 1998. Effects of monotone and nonmonotone attrition on parameter estimates in regression models with educational data: Demographic effects on achievement, aspirations and attitudes. Journal of Human Resources 33, 555-574.

Burns, N., Kinder, D.R., Rosenstone, S.J., Sapiro, V., American National Election Studies., 2001. National Election Studies, 2000: Pre-/Post-Election Study. University of Michigan, Center for Political Studies, Ann Arbor, MI.

Casper, L.M., L.E. Bass. 1998. Voting and registration in the election of November 1996. Current Population Reports, Series P-20, No. 504. US Bureau of the Census. US Government Printing Office, Washington, DC.

Couper, M.P., 1998. Measuring survey quality in a CASIC environment. In: Proceedings of the American Statistical Association, Survey Research Methods Section, pp. 41-49.

Curtin, R., Presser, S., Singer, E., 2005. Changes in telephone survey nonresponse over the past quarter century. Public Opinion Quarterly 69, 87-98.

de Leeuw, E., de Heer, W., 2002. Trends in household survey nonresponse: a longitudinal and international perspective. In: Groves, R.M., Dillman, D.A., Eltinge, J.L., Little, R.J.A. (Eds.), Survey Nonresponse. John Wiley \& Sons, Inc., New York, pp. 41-54.

Deming, W.E., 1953. On a probability mechanism to attain an economic balance between the resultant error of response and the bias of nonresponse. Journal of the American Statistical Association 48, 743-772.

DeBell, M., Krosnick, J.A., 2009. Computing weights for American national election study survey data. ANES Technical Report Series, No. nes012427.

Dye, J.L., 2005. Fertility of American women: June 2004. US Census Bureau.

Fienberg, S.E., Mason, W.M., 1979. Identification and estimation of age-period-cohort models in the analysis of discrete archival data. Sociological Methodology 10, 1-67.

Fitzgerald, J., Gottschalk, P., Moffitt, R., 1998. An analysis of sample attrition in panel data: the Michigan panel study of income dynamics. Journal of Human Resources 33, 251-299.

Gray, R., Campanelli, P., Deepchand, K., Prescott-Clarke, P., 1996. Exploring survey nonresponse: the effect of attrition on a follow-up of the 1984-85 health and life style survey. The Statistician 45, 163-183.

Groves, R.M., 2006. Nonresponse rates and nonresponse bias in household surveys. Public Opinion Quarterly 70, 646-675.

Groves, R.M., Couper, M., 1998. Nonresponse in Household Interview Surveys. John Wiley \& Sons, Inc., New York.

Groves, R.M., Peytcheva, E., 2008. The impact of nonresponse rates on nonresponse bias: a meta-analysis. Public Opinion Quarterly 72, 167-189.

Groves, R.M., Brick, J.M., Couper, M., Kalsbeek, W., Harris-Kojetin, B., Kreuter, F., Pennell, B.-E., Raghunathan, T.E., Schouten, B., Smith, T.W., Tourangeau, R., Bowers, A., Jans, M., Kennedy, C., Levenstein, R., Olson, K., Peytcheva, E., Ziniel, S., Wagner, J., 2008. Issues Facing the Field: Alternative Practical Measures of Representativeness of Survey Respondent Pools. Survey Practice 1, no pp.

Hobbs, F., Stoops, N., 2002. Demographic Trends in the 20th Century. US Department of Commerce.

Holder, K. 2006. Voting and registration in the election of November 2004. Current Population Reports, Series P-20, No. 556, US Bureau of the Census. US Government Printing Office, Washington, DC.

Jamieson, A., H.B. Shin, and J. Day. 2002. Voting and registration in the election of November 2000. Current Population Reports, Series P-20, No. 542, US Bureau of the Census. US Government Printing Office, Washington, DC.

Kalton, G., Citro, C., 1993. Panel surveys: adding the fourth dimension. Survey Methodology 19, 205-215.

Lepkowski, J.M., Couper, M.P., 2002. Nonresponse in the second wave of longitudinal household surveys. In: Groves, R.M., Dillman, D.A., Eltinge, J.L., Little, R.J.A. (Eds.), Survey Nonresponse. John Wiley \& Sons, Inc., New York, pp. 259-273.

Loosveldt, G., Carton, A., Evaluation of nonresponse in the belgian election panel study '91-'95. In: 52nd Annual Conference of the American Association for Public Opinion Research, Norfolk, Virginia, 1997, pp. 1017-1022.

Loosveldt, G., Pickery, J., Billiet, J., 2002. Item nonresponse as a predictor of unit nonresponse in a panel survey. Journal of Official Statistics 18, 545-557.

Luevano, P., 1994. Response Rates in the National Election Studies, 1948-1992, American National Election Studies Technical Reports, No. 44. University of Michigan, Ann Arbor.

Lynn, P., Buck, N., Burton, J., Jackle, A., Laurie, H., 2005. A Review of Methodological Research Pertinent to Longitudinal Survey Design and Data Collection. University of Essex, Colchester.

Mackun, P.J., 2005. Population change in metropolitan and micropolitan statistical areas: 1990-2003. US Census Bureau.

MaCurdy, T., Mroz, T., Gritz, R.M., 1998. An evaluation of the national longitudinal survey on youth. Journal of Human Resources $33,345-436$.

McDonald, M.P., 2003. On the overreport bias of the national election study turnout rate. Political Analysis 11, 180-186. 
Miller, W.E., American National Election Studies, 1980. American National Election Studies, 1980 Pre-Post Election Study Center for Political Studies. University of Michigan, Ann Arbor, MI. pp. dataset.

Miller, W.E., American National Election Studies, 2000a. American National Election Study, 1984. Inter-university Consortium for Political and Social Research.

Miller, W.E., American National Election Studies, 2000b. American National Election Study, 1988. 2000. Inter-university Consortium for Political and Social Research.

Miller, W.E., Miller, A.H., 1977. American National Election Studies: 1976 Pre-Post Election Study. Center for Political Studies. University of Michigan, Ann Arbor, MI.

Miller, W., Miller, A., Brody, R., Dennis, J., Kovenock, D., Shanks, M., 1972. American National Election Studies: 1972 Pre-Post Election Study. Center for Political Studies. University of Michigan, Ann Arbor, MI.

Miller, W.E., Kinder, D.R., Rosenstone, S.J., American National Election Studies, 1993. American National Election Study, 1992: Pre- and Post-Election Survey (Enhanced with 1990 and 1991 data). University of Michigan, Center for Political Studies, and Inter-university Consortium for Political and Social Research Ann Arbor, MI, pp. Computer file.

Mirowsky, J., Reynolds, J.R., 2000. Age, depression, and attrition in the national survey of families and households. Sociological Methods and Research 28, 476-504.

Peracchi, F., 2002. The European community household panel: a review. Empirical Economics 27, 63-90.

Political Behavior Program, University of Michigan, 1968. American National Election Studies, 1968 Pre-Post Election Study. Survey Research Center, Political Behavior Program. University of Michigan, Ann Arbor, MI.

Political Behavior Program, the Survey Research Center of the Institute of Social Research, University of Michigan, 1999. American National Election Studies, 1964 Pre-Post Election Study. University of Michigan, Center for Political Studies, Ann Arbor, MI.

Presser, S., Traugott, M.W., Traugott, S., Vote "Over" reporting in surveys: the records or the respondents. In: International Conference on Measurement Errors, Tucson, AZ, 1990.

Rosenstone, S.J., Kinder, D.R., Miller, W.E., American National Election Studies, 1997. American National Election Study, 1996. Center for Political Studies. Institute for Social Research, The University of Michigan, Ann Arbor, MI.

Sharot, T., 1991. Attrition and rotation in panel surveys. The Statistician 40, 325-331.

Steeh, C.G., 1981. Trends in nonresponse rates, 1952-1979. Public Opinion Quarterly 45, 40-57.

Steeh, C.G., Kirgis, N., Cannon, B., DeWitt, J., 2001. Are they really as bad as they seem? Nonresponse rates at the end of the twentieth century. Journal of Official Statistics 17, 227-247.

Stoops, N., 2004. Educational attainment in the United States: 2003. US Census Bureau.

Traugott, M.W., Katosh, J.P., 1979. Response validity in surveys of voting behavior. Public Opinion Quarterly 43, 359-377.

US Bureau of the Census, 1965. Voter participation in the national election: November 1964. Current Population Reports, Series P-20, No. 143. US Government Printing Office, Washington, DC.

US Bureau of the Census. 1969. Voting and registration in the election of November 1968. Current Population Reports, Series P-20, No. 192. US Government Printing Office, Washington, DC.

US Bureau of the Census. 1973. Voting and registration in the election of November 1972. Current Population Reports, Series P-20, No. 253. US Government Printing Office, Washington, DC.

US Bureau of the Census. 1978. Voting and registration in the election of November 1976. Current Population Reports, Series P-20, No. 322. US Government Printing Office, Washington, DC.

US Bureau of the Census. 1982. Voting and registration in the election of November 1980. Current Population Reports, Series P-20, No. 370. US Government Printing Office, Washington, DC.

US Bureau of the Census. 1986. Voting and registration in the election of November 1984. Current Population Reports, Series P-20, No. 405. US Government Printing Office, Washington, DC.

US Bureau of the Census. 1989. Voting and registration in the election of November 1988. Current Population Reports, Series P-20, No. 440. US Government Printing Office, Washington, DC.

US Bureau of the Census. 1993. Voting and registration in the election of November 1992. Current Population Reports, Series P-20, No. 466. US Government Printing Office, Washington, DC.

US Census Bureau, 2008. Statistical Abstract of the United States: 2008, Washington, DC.

Voogt, R., 2005. An alternative approach to correcting response and nonresponse bias in election research. Acta Politica 40, 94-116.

Voogt, R.J.J., Saris, W.E., 2003. To participate or not to participate: the link between survey participation, electoral participation, and Political Interest. Political Analysis 11, 164-179.

Waterton, J., Lievesley, D., 1987. Attrition in a panel study of attitudes. Journal of Official Statistics 3, 267-282.

Watson, N., Wooden, M., 2009. Identifying factors affecting longitudinal survey response. In: Lynn, P. (Ed.), Methodology of Longitudinal Surveys. John Wiley \& Sons, Ltd., Chichester, West Sussex (Chapter 10).

Westat, 1998. SIPP Quality Profile 1998. US Department of Commerce, US Census Bureau, Washington, DC. 